\title{
A Study on the Growth of Juveniles of Tiger Prawn, Penaeus monodon (Fabricius) Under Different Photoperiods
}

\author{
Anil Chatterji ${ }^{1}$, Siddhartha Pati ${ }^{* 1,2}$ and Dash BP2 \\ ${ }^{1}$ Malkolak Institute of Marine Studies, Goa, India \\ ${ }^{2}$ Department of Bioscience and Biotechnology, Fakir Mohan University, Balasore, India
}

\begin{abstract}
The growth of the juveniles of Penaeus monodon (Fabricius) was studied for a period of 77 days under light and dark conditions in the laboratory. Length and weight relation showed that the weight of the juveniles increased more rapidly under the dark condition as compared to the light condition. The exponent values (b) obtained for dark condition was higher $(b=3.99 ; r=0.99)$ as compared to light condition $(b=1.52 ; r=0.92)$. The maximum growth in weight was observed between $7^{\text {th }}$ and $10^{\text {th }}$ weeks under dark condition whereas, between $7^{\text {th }}$ and $9^{\text {th }}$ weeks under light condition. The growth pattern with respect to weight fitted well with von Bertalanffy's growth equation and showed observed values closed to calculated values.
\end{abstract}

Keywords: Photoperiod; Growth; Penaeus monodon

\section{Introduction}

Light is one of the most important environmental factors that regulate the burrowing and reproductive behavior of the penaeid prawns [1-8]. Rhythmic behaviour including biological activity of the shrimp affected significantly by the unfavourable conditions of the environment such as continuous bright light [5]. Aaron and Wisby [9] found that the juveniles (50-105 mm TL) of Penaeus duorarum showed a positive attraction towards dim light during full and new moon phases.

The effect of continuous dark and light conditions on the biological behaviour of the juveniles of penaeid shrimp has not been studies in detail. Hence an attempt was made in the present experiment to demonstrate the effect of light and dark conditions on the growth of juveniles of Penaeus monodon (Fabricius).

\section{Materials and Methods}

In the present investigation, the juveniles of Penaeus monodon (Fabricius) were collected from a commercial hatchery and brought to the laboratory for further studies. The juveniles were acclimated to the laboratory conditions for a period of one week. All experiments were conducted in glass aquarium tanks of 20 liter capacity under total dark condition (0.0lx : day and light) and total light condition (384 lx : day and night). In each tank, 10 juveniles of $P$. monodon of uniform weight (0.1-0.15 g) and length (14.5-15.5 mm) were maintained at a constant salinity of $30 \mathrm{ppt}, 8.2 \mathrm{pH}$ and $30+2^{\circ} \mathrm{C}$ temperature. The juveniles were fed twice a day with a commercial pelleted feed at the rate of $10 \%$ of their biomass. Length and weight of each juvenile were recorded at weekly intervals. Before recording the length and weight, the juveniles were kept on a plotting paper to remove the excess water. Seawater in the experimental tanks was changed twice with fresh filtered seawater of the same salinity, $\mathrm{pH}$ and temperature. The unconsumed food was siphoned out every day to avoid contamination of the water and the experiment was completed within 77 days.

The relationship between total length and weight of the juveniles under total light and dark conditions was calculated by the regression equation (Least square method). Weight of each juvenile at each length interval was calculated by the allometric equation $\mathrm{W}=\mathrm{aL}^{\mathrm{b}}$ (where $\mathrm{W}$ is the weight of the juveniles, $L$; the length and 'a' and ' $b$ ' are additive and multiplying constants, respectively). Length and weight curves were plotted separately for total light and total dark conditions. Mean weekly weight attained by the juveniles was estimated from the difference in the initial and final weights whereas; specific growth rate was calculated by the method as described by Chatterji et al. [10]

Asymptotic weight $(\mathrm{W} \alpha)$ attained by the juveniles was determined graphically by plotting weight at $\mathrm{W}_{\mathrm{t}}$ against $\mathrm{W}_{\mathrm{t}+1}$. The computed values of growth parameters for light and dark conditions were fitted with the following von Bertalanffy's growth equation:

$$
\mathrm{W}_{\mathrm{t}}=\mathrm{Wa}\left[1-\mathrm{e}^{-\mathrm{K}(\mathrm{t}-\mathrm{to})}\right]
$$

Where $\mathrm{W}_{\mathrm{t}}$ is the weight at time $\mathrm{t}, \mathrm{Wa}=$ the asymptotic weight, ' $\mathrm{e}$ ' = the base of the natural logarithm, $\mathrm{K}=$ the coefficient of catabolism, ' $\mathrm{t}$ ' $=$ the time of observation and ' $t$ '.

$=$ the time at which the juveniles belong to zero gram weight. The calculation of ' $t_{0}$ ' was based on the following formula of Ricker [11]:

$$
\mathrm{t}_{\mathrm{o}}=\left[\log _{\mathrm{e}} \mathrm{Wa}+\mathrm{Kt} \mathrm{o}_{\mathrm{o}}\right]-\log _{\mathrm{e}} \mathrm{W} / \mathrm{K}
$$

The value of $\log _{e} \mathrm{~W} \alpha+\mathrm{Kt}_{\mathrm{o}}$ is the $\mathrm{y}$-axis intercept where $\log _{\mathrm{e}}(\mathrm{W} \alpha-$ $\mathrm{W}_{\mathrm{t}}$ ) is plotted against the mean weights

\section{Results}

A parabolic relationship was obtained when the values of length and weight of the juveniles were plotted separately during each week under light and dark conditions. The smooth curves in Figures 1a and $2 \mathrm{a}$ showed the calculated weights at each length intervals whereas the straight lines in Figures $1 \mathrm{~b}$ and $2 \mathrm{~b}$ showed the calculated regression lines. The differences in increase in length were not well marked up to $30 \mathrm{~mm}$ length under light and dark conditions (Figures 1a and 2a).

*Corresponding author: Siddhartha Pati, Department of Bioscience and Biotechnology, Fakir Mohan University, Balasore, India, Tel: 06782-275875; E-mail: patisiddhartha@gmail.com

Received August 31, 2015; Accepted September 15, 2015; Published December 15,2015

Citation: Chatterji A, Pati S, Dash BP (2015) A Study on the Growth of Juveniles of Tiger Prawn, Penaeus monodon (Fabricius) Under Different Photoperiods. J Aquac Res Development 6: 385. doi:10.4172/2155-9546.1000385

Copyright: $\odot 2015$ Chatterji A, et al. This is an open-access article distributed under the terms of the Creative Commons Attribution License, which permits unrestricted use, distribution, and reproduction in any medium, provided the original author and source are credited. 
Citation: Chatterji A, Pati S, Dash BP (2015) A Study on the Growth of Juveniles of Tiger Prawn, Penaeus monodon (Fabricius) Under Different Photoperiods. J Aquac Res Development 6: 385. doi:10.4172/2155-9546.1000385

Page 2 of 5

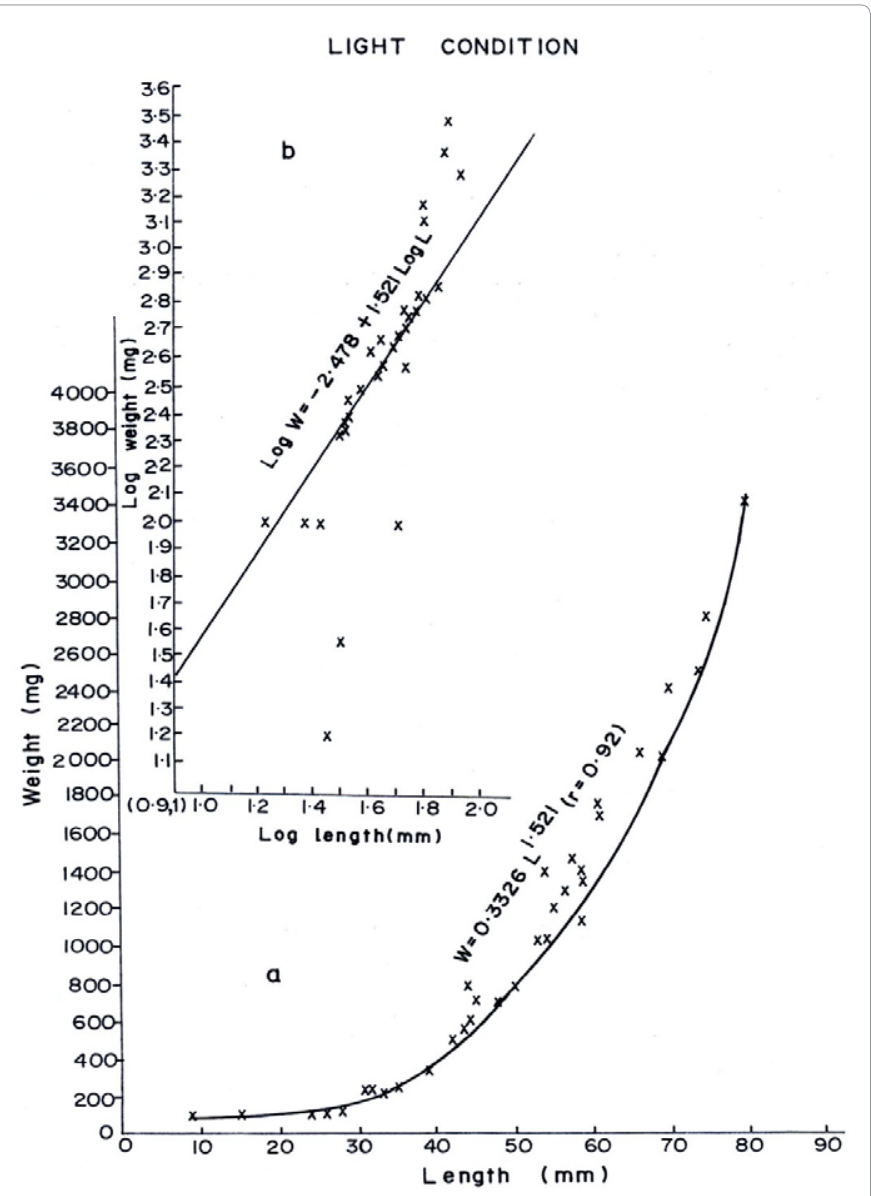

a) Smooth curve represent the calculated weight of juvenile

b) The straight line represents the calculated regression line of log weight on log length of juvenile

Figure 1: The length and weight relationship of juveniles, $P$. monodon under light and dark Conditions.

However, the increase in weight was relatively more rapid under dark conditions as compared to light conditions as evident in Figures 1a and 2a. It was observed while calculating the regressions equations that the exponent $(b)$ value was greater under dark condition $(b=3.99 ; r=0.99)$ as compared to the light condition $(b=1.562 ; \mathrm{r}=0.92)$.

The mean weekly data collected for 77 days for length and weight under light and dark conditions are presented in Figures 3 and 4 respectively. Under dark conditions, the length of the juvenile shrimp was rapid up to a period of six weeks and then it slowed down at the later phase (Figure 3). However, the pattern of increment in weight showed a higher value under dark condition as compared to the light condition between the $7^{\text {th }}$ and $10^{\text {th }}$ weeks (Figure 4).

The relative growth in weight showed a decreasing trend from 37.5 to $10.7 \%$ under light condition and 33.3 to $10.2 \%$ under dark condition (Table 1). Similarly the specific growth rate also showed a decreasing pattern from 46.9 to $11.0 \%$ under light condition as compared to dark condition ( 40.4 to $10.7 \%$ ) (Table 1 ). The maximum increment in relative growth was noticed during the $8^{\text {th }}$ week for dark condition and $9^{\text {th }}$ week for the light condition (Table 1).

The asymptotic weight (Wa), calculated after applying FordWalford equation is presented in Figure $5 \mathrm{a}$ and $5 \mathrm{~b}$ for light condition and Figure $6 \mathrm{a}$ and $6 \mathrm{~b}$ for the dark condition. It is evident that under dark condition, the growth in weight was more rapid $(\mathrm{W} \alpha=200 \mathrm{~g})$ as compared to light condition ( $\mathrm{Wa}=190 \mathrm{~g}$ ).

In the present study the calculated values obtained after applying von Bertalanffy's growth equation for the juvenile shrimps, showed a close agreement with the average observed weight under total light and dark conditions (Table 2). This showed that von Bertalanffy's growth equation fitted well in expressing the growth pattern of the juveniles of $P$. monodon under light and dark conditions.

\section{Discussion}

Environmental factors including light and dark conditions have been reported to play a significant role on the secretion of the melanophores, hormone and maintenance of water equilibrium, formation of secondary sexual feature, thyroid activity and growth of the animals [12-17]. It has also been observed that many aquatic animals experience change in their metabolic functions due to internal de-synchronization of some of the physiological processes under dark and light conditions [18].

Although light and dark conditions play a significant role in controlling various physiological processes of aquatic animals in an ecosystem no comprehensive study has so far, been done to show the effect of light and dark conditions effecting directly on the growth of juveniles shrimp. However, the juveniles of $M$. rosenbergii reared under continuous darkness (12 hr light: $12 \mathrm{hr}$ darkness; $16 \mathrm{hr}$ light:

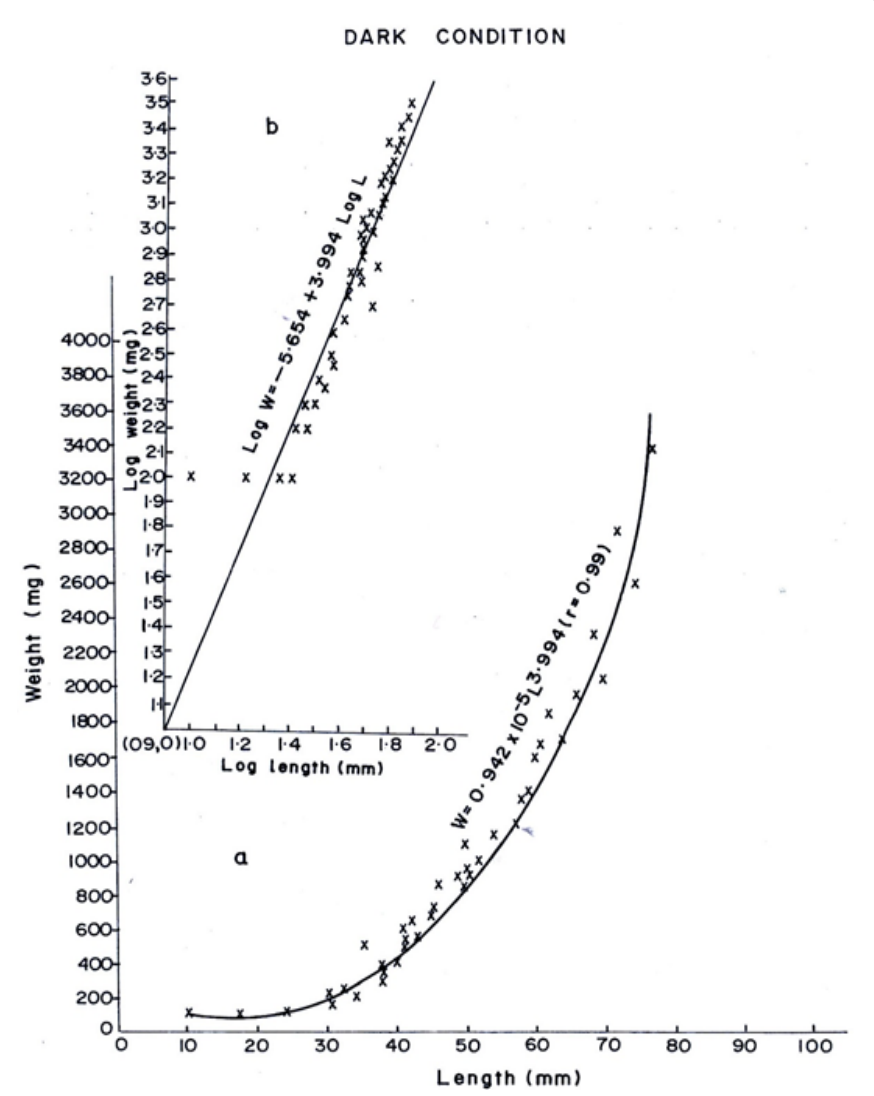

a) Smooth curve represent the calculated weight of juvenile

b) The straight line represents the calculated regression line of log weight on log length of juvenile.

Figure 2: The length and weight relationship of juvenile of $P$. monodon under dark Conditions. 


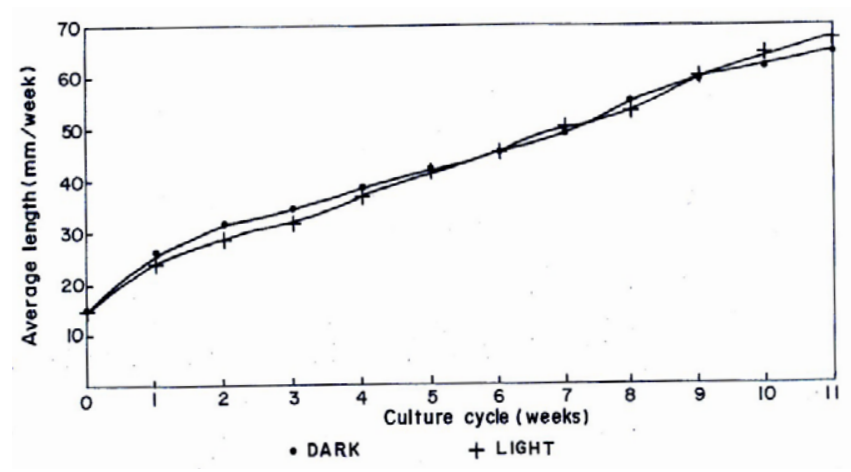

Figure 3: Mean weekly lengths $(\mathrm{mm})$ attained by juveniles of $P$. monodon under light and dark conditions.

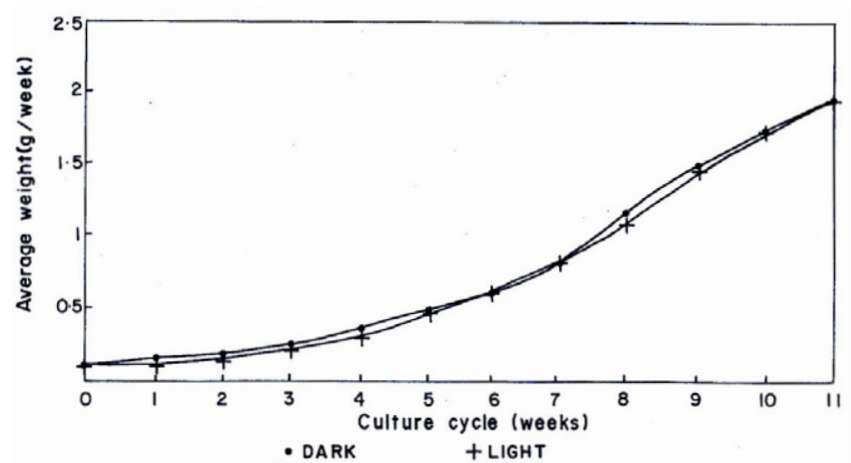

Figure 4: Mean weekly weights $(\mathrm{g})$ attained by juveniles of $P$. monodon under light and dark conditions.

\begin{tabular}{|l|l|l|l|l|l|l|}
\hline \multirow{2}{*}{ Weeks } & \multicolumn{2}{|l|}{ Relative growth (\%) } & \multicolumn{2}{l|}{ Specific growth (\%) } & \multicolumn{2}{l|}{ Growth increment (\%) } \\
\cline { 2 - 7 } & $\begin{array}{l}\text { Light } \\
\text { period }\end{array}$ & $\begin{array}{l}\text { Dark } \\
\text { period }\end{array}$ & $\begin{array}{l}\text { Light } \\
\text { period }\end{array}$ & $\begin{array}{l}\text { Dark } \\
\text { period }\end{array}$ & $\begin{array}{l}\text { Light } \\
\text { period }\end{array}$ & $\begin{array}{l}\text { Dark } \\
\text { period }\end{array}$ \\
\hline 1 & - & 33.3 & - & 22.9 & - & 0.05 \\
\hline 2 & 37.5 & 16.6 & 46.9 & 15.3 & 0.06 & 0.03 \\
\hline 3 & 23.8 & 28.0 & 27.1 & 10.7 & 0.05 & 0.07 \\
\hline 4 & 34.3 & 32.4 & 42.1 & 40.4 & 0.11 & 0.12 \\
\hline 5 & 30.4 & 26.0 & 36.2 & 18.2 & 0.14 & 0.30 \\
\hline 6 & 26.9 & 19.3 & 31.4 & 32.8 & 0.17 & 0.12 \\
\hline 7 & 25.0 & 20.5 & 28.7 & 39.2 & 0.21 & 0.16 \\
\hline 8 & 21.4 & 35.0 & 24.1 & 30.1 & 0.23 & 0.42 \\
\hline 9 & 26.7 & 20.5 & 31.0 & 21.5 & 0.39 & 0.31 \\
\hline 10 & 16.0 & 14.2 & 17.5 & 22.9 & 0.28 & 0.25 \\
\hline 11 & 10.7 & 10.2 & 11.0 & 10.7 & 0.21 & 0.20 \\
\hline
\end{tabular}

Table 1: Relative growth, specific growth and growth increment of the weight under total light and dark conditions.

$8 \mathrm{hr}$ darkness and $20 \mathrm{hr}$ light: $4 \mathrm{hr}$ darkness) for 110 days showed a higher growth and survival rate under dark condition than any other photoperiod conditions [19]. Similarly, Tay-Hc [20] reported that the starved larvae of $P$. esculatus kept under different photoperiod conditions ( $24 \mathrm{hr}$ dark, $24 \mathrm{hr}$ light and 12:12 hr dark/light) showed rapid growth in the 12:12 dark/light conditions. Continuous light conditions showed a slower growth in the larvae of P. esculatus [20]. The present study corroborates the earlier findings where higher growth rate in penaeid shrimps was recorded under dark conditions.

The light intensity affected the growth of the shrimp (Fenneropenaeus chinensis) by influencing mainly the food conversion efficiency (FCE)
[21]. The specific growth rate (SGR) in juvenile of the same shrimp was measured over a period of 35 days under different light intensities i.e. $0,50,300,1300$ and $5500 \mathrm{~lx}$ by Fang et al. [21]. The shrimps were reported to grow faster under lesser light condition. Additionally these workers have found that the SGR of the shrimp under $5500 \mathrm{~lx}$ was only $29.4 \%, 27.1 \%, 21.1 \%$ and $19.7 \%$ of those under $0,1300,50$ and $300 \mathrm{~lx}$, respectively $(\mathrm{P}<0.05)$. The shrimp under $5500 \mathrm{~lx}$ showed a lower feed intake (FI) and FCE resulting in a lower SGR values [21]. However Fang et al. [22] in another experiment found that when the shrimps (wet weight: $0.945 \pm 0.005 \mathrm{~g}$ ) were kept in glass aquaria under four photoperiod conditions ( 0 light/ 24 dark, 24 light/ 0 dark, 10 light/14 dark, and 14 light/10 dark) for 35 days, no significant difference in specific growth rate, food intake, and food conversion efficiency among the shrimps under the four photoperiods was recorded. But the moulting frequency of the shrimps under 14 light/10 dark and 10 light/14 dark were significantly higher than those under 0 light $/ 24$ dark, 24 light/ 0 dark [22]. The difference in growth of the shrimps among four photoperiod treatments was not significant.

The juveniles of Jasus edwardsii (1-10 g weight) were subjected to five photoperiod conditions [0L(light):24D(dark); 6L:18D; 12L:12D; 18L:6D; 24L:0D] during a 112-day of experimental period where growth, survival, colour and food consumption were examined by Crear et al. [23]. The specimens of J. edwardsii showed lower mean weight and specific growth rate under 6L:18D and 24L:0D photoperiods $(\mathrm{P}<0.05)$ than any other treatments. Crear et al. [23] have not found any photoperiod effect on the survival or colour of lobsters. Major

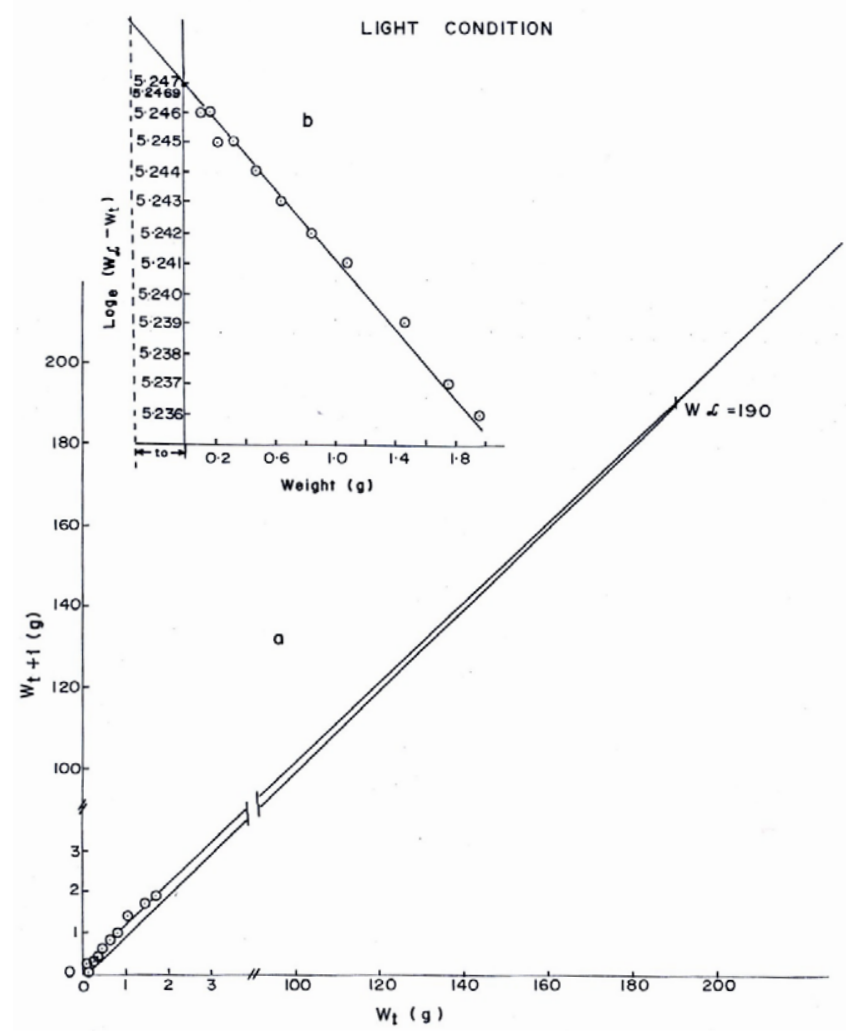

Figure 5a: Ford-Walford plot of growth of $P$. monodon with reference to weight under light conditions. $5 \mathbf{b}: \log _{\mathrm{e}}\left(\mathrm{W} \alpha-W_{t}\right)$ plotted against weight for estimation of ' $\mathrm{t}$ ' ' for $P$. monodon under light condition 


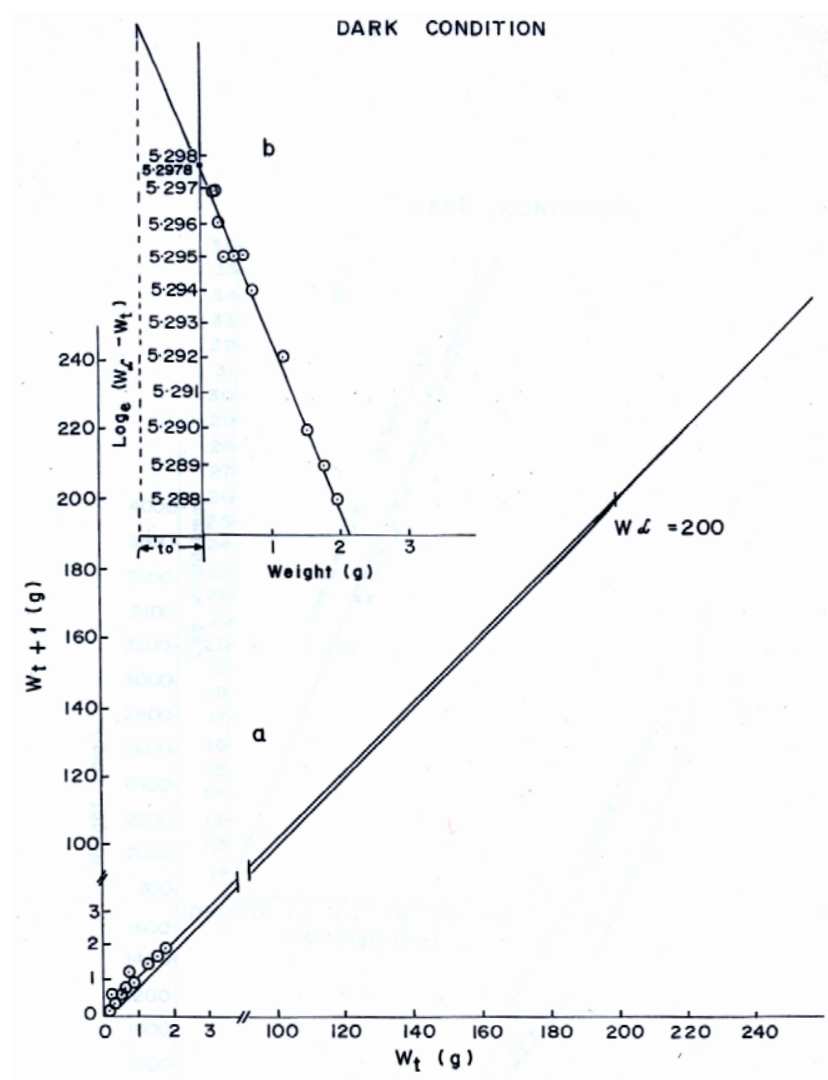

Figure 6a: Ford-Walford plot of growth of $P$. monodon with reference to weigh under dark conditions. $\mathbf{6 b}: \log _{\mathrm{e}}\left(\mathrm{Wa}-\mathrm{W}_{\mathrm{t}}\right)$ plotted against weight for estimation of 't $\mathrm{o}$ ' for $P$. monodon under dark condition

\begin{tabular}{|l|l|l|l|l|}
\hline Weeks & Light condition & \multicolumn{3}{l|}{ Dark condition } \\
\hline & $\begin{array}{l}\text { Average observed } \\
\text { weight (g) } \\
{[ \pm \text { SD }]}\end{array}$ & $\begin{array}{l}\text { Weight } \\
\text { determined } \\
\text { by using von } \\
\text { Bertalanffy's } \\
\text { growth equation }\end{array}$ & $\begin{array}{l}\text { Average } \\
\text { observed } \\
\text { weight }(g) \\
{[ \pm \text { SD] }}\end{array}$ & $\begin{array}{l}\text { Weight } \\
\text { determined } \\
\text { by using von } \\
\text { Bertalanffy's } \\
\text { growth equation }\end{array}$ \\
\hline Initial & $0.10 \pm 00$ & - & $0.10 \pm 00$ & - \\
\hline 1 & $0.10 \pm 00$ & 0.20 & $0.15 \pm 0.05$ & 0.23 \\
\hline 2 & $0.16 \pm 0.048$ & 0.39 & $0.18 \pm 0.06$ & 0.43 \\
\hline 3 & $0.21 \pm 0.030$ & 0.58 & $0.25 \pm 0.05$ & 0.63 \\
\hline 4 & $0.32 \pm 0.124$ & 0.77 & $0.37 \pm 0.14$ & 0.83 \\
\hline 5 & $0.46 \pm 0.149$ & 0.96 & $0.50 \pm 0.20$ & 1.03 \\
\hline 6 & $0.63 \pm 0.228$ & 1.15 & $0.62 \pm 0.22$ & 1.23 \\
\hline 7 & $0.84 \pm 0.272$ & 1.34 & $0.78 \pm 0.35$ & 1.43 \\
\hline 8 & $1.07 \pm 0.343$ & 1.53 & $1.20 \pm 0.51$ & 1.63 \\
\hline 9 & $1.46 \pm 0.438$ & 1.72 & $1.51 \pm 0.59$ & 1.83 \\
\hline 10 & $1.74 \pm 0.498$ & 1.90 & $1.76 \pm 0.75$ & 2.02 \\
\hline 11 & $1.95 \pm 0.650$ & 2.09 & $1.96 \pm 0.80$ & 2.22 \\
\hline
\end{tabular}

Table 2: Average observed weight, calculated weight for total light and dark conditions.

feeding activity was found during dark periods for the lobsters exposed to photoperiods that had light and dark regimes.

Series of experiments were carried out on the larvae and juveniles of Lates calcarifer by Barlow et al. [24] to determine the effect of extended periods of light on the growth, survival, feeding pattern and daily feed consumption. They found that the larvae 2-10 days old grew relatively faster under conditions of 8,16 and $24 \mathrm{hr}$ light per day whereas larvae
8-20 days old grew significantly slower in $8 \mathrm{hr}$ light than in 16 and 24 $\mathrm{hr}$ light conditions. It has been observed that when the juveniles (11-12 $\mathrm{mm}$ total length) exposed to an extended light condition, the growth rate increased considerably during their first 8-10 days, but thereafter it became less important. There was no significant difference in the growth or survival rates in 12,18, or $24 \mathrm{hr}$ of exposure of Lates calcarifer. Downing and Litvak [25] while conducting two separate experiments had cultured larvae of haddock (Melanogrammus aeglefinus) under different photoperiods (24L : 0D or 15L : 9D) and different combinations of tank colour (black or white) with light intensity ranging from 1.1 to $18 \mu \mathrm{mols}$ ${ }^{-1} \mathrm{~m}^{-2}$. They observed that the growth in terms of standard length and body weight were higher under light conditions as compared to dark condition. This shows that animals inhabiting at the bottom need dark condition for their better growth.

The feeding rates of Mysis mixta and Praenus flexuousus on a copepod (Acartia sp) was compared under light and dark conditions by Viherluoto abd Viitasalo [26]. The feeding rates of pelagic mysids were significantly higher in total darkness than in light condition. The feeding rates of littoral mysids did not differ under the dark conditions.

The effect of light and dark cycles on the growth and mortality of Palaemon elegans under laboratory conditions has been studied by Dalley [27] who reported a significant decrease in the growth rate of the juveniles in non-circadian regime when the data were compared with 12 hours light and 12 hours dark conditions. The lower growth rate in juveniles was on account of non-circadian regimes. In the present investigations, a higher growth rate was observed under dark condition as compared to light conditions. The relationship of length and weight of juvenile shrimps under light and dark conditions was carried out primarily to understand the growth pattern of the animal. The present study showed that weight in juvenile shrimps was increased more than the cube of the length under dark conditions $(b=3.994)$. However, though the relationship was parabolic under light conditions, the weight of the shrimp increased equal to the length of juveniles $(b=1.521)$. This indicates that the juveniles of $P$. monodon grow faster under dark condition as compared to light condition which strongly supports our results.

\section{Acknowledgements}

The authors (AC, SP) are thankful to the Chairman, Malkolak Knowledge Center, Hyderabad and (BPD, GCB) to the Vice-Chancellor, Fakir Mohan University, Balasore for the facilities and encouragements.

\section{References}

1. Dall W (1958) Observations on the biology of the Greentail Prawn Metapenaeus mastersii (Haswell) (Crustacea:Decapoda:Penaeidae) Aust J Mar Freshwat Res 9: 111-134.

2. Le Guen JC, Cronier A (1968) Contribution a l'e'tide du rythme quotidien d'activité Penaeus duorarum Burkenroad (Crustacea :Decapoda :Natantia) Bull Mus Nat d'Hist 40: 342-350.

3. Hughes DA (1969) Evidence for the endogenous control of swimming in pink shrimp Penaeus duorarum. Biol Bull 136: 398-404.

4. Hughes DA (1969) Factors controlling the time of emergence of pink shrimp Penaeus duorarum. FAO Fish Rep 3: 971-981.

5. Hindley JPR (1975) Effects of endogenous and some exogenous factors on the activity of the juvenile banana prawn Penaeus merguiensis. Mar Biol 29: 1-8.

6. Moller TH, Jones DA (1975) Locomotory rhythms and burrowing habits of Penaeus semisulcatus (de Haan) and $P$. monodon (Fabricius) (Crustacea:Penaeidae). J Exp Mar Biol Ecol 18: 61-77.

7. Wickham DA, Minkler FC (1975) Laboratory observations on daily patterns of burrowing and locomotor activity of pink shrimp Penaeus duorarum brown shrimp Penaeus aztecus and white shrimp Penaeus setiferus. Contr Mar Sci 19: $21-35$. 
Citation: Chatterji A, Pati S, Dash BP (2015) A Study on the Growth of Juveniles of Tiger Prawn, Penaeus monodon (Fabricius) Under Different Photoperiods. J Aquac Res Development 6: 385. doi:10.4172/2155-9546.1000385

Page 5 of 5

8. Natarajan P (1969) Persistent locomotor rhythmicity in the prawns Penaeus indicus and $P$. monodon. Mar Biol 101 339-346.

9. Aaon RL, Wisby WJ (1964) Effects of light and moon phase on the behaviour of pink shrimp. In: Proceedings of the Gulf and Caribbean Fisheries Institute $16^{\text {th }}$ Session.

10. Chatterji A, Ansari ZA, Ingole BS, Parulekar AH (1984) Growth of the green mussel Perna viridis $\mathrm{L}$ in a seawater circulating system. Aquaculture 40: 47-55.

11. Ricker WE (1958) Handbook of computation for biological spastics of fish population. Fish Res Bd Canada Bull.

12. Sponde E (1952) Die Beeinflussung de Formeelente des Blutes durch optische Strahlung. Wiss Z. Humbolt-Univ. Berlin Math-Naturwiss Reihe 5: 17-25.

13. Surowiak J, Tilgner S (1966) The influence of white light and darkness on the percentage composition of white blood corpuscles in the peripheral blood of the white mouse (Mus musculus L) Acta Biol Crac Zool 9: 227-297.

14. Surowiak J, Tilgner S (1967) Changes in the quality of acid and alkaline phosphatase in the pituitary thyroid and adrenals of white mouse (Mus musculus $\mathrm{L}$ ) exposed to different influences of white light. Acta Biol Crac Zool 10: 149-168.

15. Surowiak J (1967) Energetyezna Czesc drog widzeni. Przegl Zool 9: 223-229.

16. Beiniarz K (1973) Effects of light and darkness on incubation of eggs length weight and sexual maturity of sea trout (Salmo trutta L.) brown trout (Salmo trutta fario L.) and rainbow trout (Salmo indeus Gibbons) Aquaculture 2: 299315.

17. Pittendrigh CS (1960) Circadian rhythms and the circadian organization of living systems. Cold Spring Harb Symp Quant Biol 25: 159-184.
18. Pittendrigh CS (1961) On temporal organization in living systems. Harvey Lect 59: 93-125.

19. Withyachumnarnkul B, Poolsanguan B, Poolsanguan W (1990) Continuous darkness stimulates body growth of the juvenile giant fresh water prawn $M$. rosenbergii de man. Chrono Biol 7: 93-97.

20. Tay-Hc (1992) Effect of photoperiod on the growth survival and development of P. esculatus larvae. Aust Soc Fish Biol 22: 56-57.

21. Wang F, Dong S, Dong S, Huang G, Zhu C, Mu Y (2004) The effect of light intensity on the growth of Chinese shrimp Fenneropenaeus chinensis. Aquaculture 234: 475-483.

22. Fang W, Shuang-Lin D, Shao-Shuai D, Guo-Qiang H (2005) Effects of photoperiod on the molting and growth of juvenile Chinese shrimp Fenneropenaeus chinensis. J Fish Sci China 111: 60-70.

23. Crear BJ, Hart PR, Thomas CW (2003) The effect of photoperiod on growth survival, colour and activity of juvenile southern rock lobster Jasus edwardsii. Aquaculture Research 34: 439-444.

24. Barlow CG, Pearce MG, Rodgers LJ, Clayton P (1995) Effects of photoperiod on growth, survival and feeding periodicity of larval and juvenile barramundi Lates calcarifer (Bloch). Aquaculture 138: 59-168.

25. Downing G, Litvak MK (2000) The effect of photoperiod tank colour and light intensity on growth of larval haddock. Aquaculture International 7: 369-382.

26. Viherluoto M, Viitasalo M (2001) Effect of light on the feeding rates of pelagic and littoral mysid shrimps: a trade-off between feeding success and predation avoidance. J Exp Mar Biol Ecol 261: 237-244.

27. Dalley R (1980) Effects of non-circadian light/dark cycles on the growth and moulting of Palaemon elegans reared in the laboratory. Mar Biol 56: 71-78. 